\title{
TÉCNICAS DE PROCESSAMENTO DE IMAGENS PARA TREINAMENTO DE FOTOINTERPRETES NA AVALIAÇÃO VISUAL DE ÁREAS ÚMIDAS E DE MANCHAS E CICATRIZES DE QUEIMADAS OU INCÊNDIOS
}

\author{
Isadora Taborda Silva ${ }^{1}$; Dhonatan Diego Pessi²; \\ Normandes Matos da Silva ${ }^{3}$; Camila Leonardo \\ Mioto $^{4}$; Eliane Guaraldo ${ }^{5}$; Antonio Conceição \\ Paranhos Filho ${ }^{6}$
}

\begin{abstract}
${ }^{1}$ Mestre em Tecnologias Ambientais, Programa de PósGraduação em Tecnologias Ambientais, Universidade Federal de Mato Grosso do Sul (UFMS), Campo Grande/MS, Brasil.

ORCID: https://orcid.org/0000-0001-9053-4329

Email: isah.taborda@gmail.com
\end{abstract}

${ }^{2}$ Doutorando em Tecnologias Ambientais, Programa de PósGraduação em Tecnologias Ambientais, Universidade Federal de Mato Grosso do Sul (UFMS), Campo Grande/MS, Brasil.

ORCID: http://orcid.org/0000-0003-0781-785X

Email: dhonatan.diego@ufms.br

${ }^{3}$ Doutor em Ecologia de Ecossistemas Terrestres e Aquáticos pela USP, Professor Associado do Instituto de Ciências Agrárias e Tecnológicas (ICAT), Universidade Federal de Rondonópolis (UFR), Rondonópolis/MS, Brasil.

ORCID: $\underline{\text { https://orcid.org/0000-0002-4631-9725 }}$

Email: normandes@ufr.edu.br

${ }^{4}$ Doutora em Saneamento Ambiental e Recursos Hídricos pela UFMS, Professora Adjunta A2 do Instituto de Ciências Agrárias e Tecnológicas (ICAT), Universidade Federal de Rondonópolis (UFR), Rondonópolis/MS, Brasil.

ORCID: https://orcid.org/0000-0002-6951-9527

Email: ea.mioto@gmail.com

${ }^{5}$ Doutora em Estruturas Ambientais Urbanas pela USP, Professora Associada da Faculdade de Engenharias, Arquitetura e Urbanismo e Geografia (FAENG), Universidade Federal de Mato Grosso do Sul (UFMS), Campo Grande/MS, Brasil.

ORCID: https://orcid.org/0000-0003-2526-1293

Email: eliane.guaraldo@gmail.com
${ }^{6}$ Livre-Docente pelo Instituto de Geociências da USP, Professor Titular da Faculdade de Engenharias, Arquitetura e Urbanismo e Geografia (FAENG), Universidade Federal de Mato Grosso do Sul (UFMS), Campo Grande/MS, Brasil.

ORCID: https://orcid.org/0000-0002-9838-5337

Email: antonio.paranhos@ufms.br

\section{Resumo}

Áreas úmidas são um dos ecossistemas mais valiosos da Terra, que estão submetidas a forte pressão antrópica (queimadas) e processos naturais como os incêndios. O Pantanal Sul-matogrossense é um exemplo. O monitoramento em larga escala de áreas úmidas é de grande importância, mas também desafiador. Utilizou-se acervo de imagens do satélite Sentinel-2 cena de 11 de setembro de 2018, para caracterização e monitoramento do Pantanal Sul-mato-grossense. O objetivo consistiu em avaliar técnicas de realce e de composição de bandas espectrais para a identificação de padrões na superfície de áreas úmidas e de queimadas e incêndios na borda do Pantanal Sul-mato-grossense. A pesquisa selecionou duas áreas amostrais submetidas ao processo de realce espacial utilizando a técnica de reamostragem por pixels. Recomenda-se a composição SWIR 2M(12)NIR(8)BLUE(2) como a mais adequada para interpretação visual de áreas úmidas e de cicatrizes e manchas de queimadas ou incêndios. A interpretação visual é um recurso ágil para uma primeira aproximação no processo de avaliação e tomada de decisão em termos de ações de monitoramento espacial e temporal em áreas úmidas.

Palavras-chave: Áreas alagáveis; Pantanal; geoprocessamento.

IMAGE PROCESSING TECHNIQUES FOR TRAINING PHOTOINTERPRETERS IN VISUAL ASSESSMENT OF WETLANDS AND BURNS OR FIRES SCARS

\section{Abstract}

Wetlands are one of the most valuable ecosystems on Earth, which are subjected to strong human pressure (burning) and natural processes such as fires. The Pantanal Sul-mato-grossense is an example. Large-scale monitoring of wetlands is of great 
importance, but also challenging. A collection of images from the Sentinel-2 satellite was used to characterize and monitor the Pantanal Sul-mato-grossense. The objective was to evaluate enhancement and spectral banding techniques for the identification of patterns on the surface of wetlands and burns and fires on the edge of the Pantanal Sul-mato-grossense. The research selected two sample areas submitted to the spatial enhancement process using the pixel resampling technique. The composition SWIR2M(12)NIR(8)BLUE(2) is recommended as the most suitable for visual interpretation of damp areas and scars and spots from burns or fires. Visual interpretation is an agile resource for a first approach to the evaluation and decisionmaking process in terms of spatial and temporal monitoring actions in wet areas.

Keywords: Wetlands; Pantanal; geoprocessing.

\section{TECNICAS DE PROCESAMIENTO DE IMÁGENES PARA ENTRENAMIENTOS DE FOTOINTERPRETACIÓN EN LA EVALUACIÓN VISUAL DE AREAS HÚMEDAS Y DE MANCHAS Y DE CICATRICES DE QUEMADURAS O INCENDIOS}

\section{Resumen}

Las zonas húmedas son uno de los ecosistemas más valiosos de la Tierra, que están sujetos a una fuerte presión humana (quemadas) y a procesos naturales como los incendios. El Pantanal Sul-mato-grossense es un ejemplo. El monitoreo a gran escala de las zonas húmedas es de gran importancia, pero también desafiante. Se utilizó una colección de imágenes del satélite Sentinel-2 para caracterizar y monitorear el Pantanal Sul-matogrossense. El objetivo fue evaluar técnicas de realce y bandas espectrales para la identificación de patrones en la superficie de zonas húmedas y del quemadas y incendios en el borde del Pantanal Sul-mato-grossense. La investigación seleccionó dos áreas de muestra sometidas al proceso de mejora espacial utilizando la técnica de remuestreo de píxeles. La composición SWIR2M(12)NIR(8)BLUE(2) se recomienda como la más adecuada para la interpretación visual de zonas húmedas y cicatrices y manchas de quemadas o incendios. La interpretación visual es un recurso ágil para una primera aproximación al proceso de evaluación y toma de decisiones en términos de acciones de monitoreo espacial y temporal en zonas húmedas.

Palabras-clave: Zonas húmedas; Pantanal; geoprocesamiento.

\section{INTRODUÇÃO}

Áreas úmidas são consideradas como um dos ecossistemas mais valiosos da Terra por suas funções ecossistêmicas, com destaque à manutenção de mananciais (Slagter et al., 2020). Suas funções ofereçam apoio crítico a pelo menos sete dos 17 principais objetivos de desenvolvimento sustentável, conforme definido pelas Nações Unidas (RAMSAR CONVENTION, 2016). Dependendo do tipo de zona úmida, algumas das suas qualidades importantes são o armazenamento e purificação de água, proteção da costa, processamento de carbono e outros nutrientes, segurança alimentar e apoio a uma ampla riqueza de espécies vegetais e animais (MILLENNIUM ECOSYSTEM ASSESSMENT, 2005; RAMSAR CONVENTION, 2016).

Atualmente as áreas úmidas estão sendo perdidas a uma taxa mais rápida do que qualquer outro ecossistema, principalmente devido à atividade humana (MILLENNIUM ECOSYSTEM ASSESSMENT, 2005). Para evitar mais perdas e implementar e avaliar políticas de preservação, é de grande importância o monitoramento e caracterização em larga escala de diferentes tipos de áreas úmidas (Slagter et al., 2020).

A água superficial contém materiais orgânicos e inorgânicos em sua composição e a sua resposta espectral é fortemente influenciada por esses materiais (Sausen, 2007). Quando pura, a maior intensidade de reflectância da energia eletromagnética corresponde à região do visível (VIS). Conforme aumenta a quantidade de sedimentos no corpo hídrico, o pico de reflectância desloca-se na direção dos maiores comprimentos de onda, aproximando-se da resposta espectral do solo, com taxa de refletância alta na região do infravermelho distante (SWIR 2).

As áreas úmidas que não possuem lâmina d'água livre apresentam valores espectrais semelhantes a áreas de incêndios e a de pastagem e vegetação rasteira secas por conta da estiagem, com mais de $40 \mathrm{~cm}$ de altura (Guo et al., 2017; Paranhos Filho et al., 2006). Sensores ópticos embarcados em satélites, com diferentes resoluções espectrais entre as regiões do VIS, VNIR (região do visível e do infravermelho próximo) e SWIR 2, como é o caso do Sentinel-2 (ESA, 2019), permitem a geração de imagens com bandas modificadas para gerar composições falsacor, realçando uma maior diferença de reflectância entre os alvos. Isso é estratégico para detecção de alvos específicos em áreas úmidas.

Entre as etapas de processamento digital está o realce que, sob os critérios subjetivos do olho humano, visa melhorar a qualidade da imagem auxiliando a discriminação dos alvos pelo fotointérprete (INPE, 2019). Para isso, as técnicas de realce modificam os níveis de cinza ou os valores digitais de uma imagem através de funções matemáticas. É um procedimento de reamostragem conhecido e amplamente utilizado em cenas Landsat (USGS) porém ainda pouco explorado em cenas Sentinel. A fotointerpretação é a técnica mais ágil de análise de imagens, se valendo da técnica de realce por geração de composições coloridas, para gerar resultados rápidos e eficientes (Silva et al., 2021)

Buscou-se avaliar o realce de bandas derivadas do satélite Sentinel 2, como suporte na identificação de padrões da superfície de áreas úmidas e de queimadas ou incêndios no Pantanal Sulmato-grossense.

\section{METODOLOGIA}

As duas áreas selecionadas para este estudo (Figura 1), estão no município de Rio Verde, Mato Grosso do Sul, e possui terrenos submetidos a diferentes pulsos de inundação, o que influencia a umidade do solo e fenologia das plantas. Também abrange áreas úmidas com características do Cerrado e do Pantanal. 


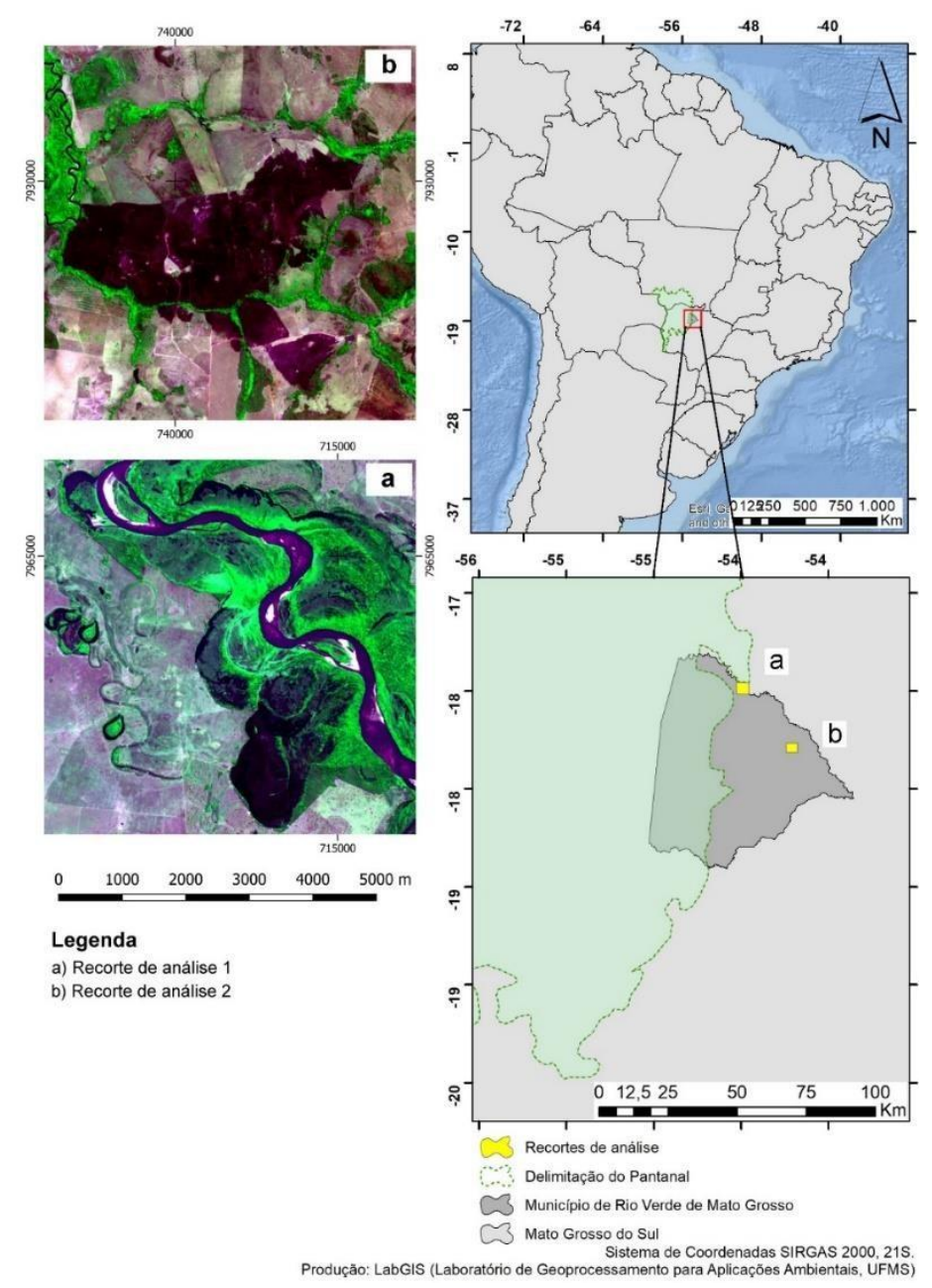

Figura 1 - Localização das duas áreas de análise na borda do Pantanal Sul-mato-grossense.

Utilizou-se cena do ano de 2018, de 11 de setembro, do satélite de média resolução Sentinel-2 (USGS, 2018), disponível na base de dados de domínio público Earth Explorer USGS (2018). O satélite é consideravelmente novo, sendo que o seu lançamento ocorreu em junho de 2015 , e possui um instrumento multiespectral (MSI) que adquire 13 faixas espectrais, sendo quatro com resolução espacial de $10 \mathrm{~m}$, seis com $20 \mathrm{~m}$ e três com $60 \mathrm{~m}$ (Figura 2). Suas imagens complementam o programa americano Landsat (USGS), porém com maior largura de faixa e maior resolução espacial. 


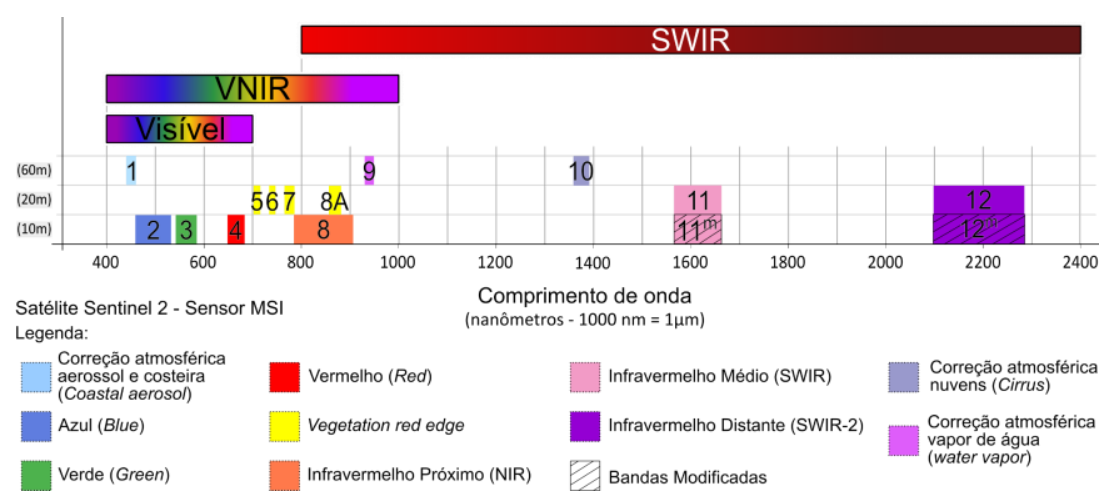

Figura 2 - Bandas Espectrais Sentinel-2 divididas entre VIS, VNIR e SWIR, com suas respectivas resoluções espaciais. Hachuradas em destaque estão as bandas modificadas $11 \mathrm{M}$ e $12 \mathrm{M}$ criadas com o realce. Os resultados obtidos podem ser verificados no capítulo 2. Fonte: Adaptado de ESA (2019).

Após o download da cena, as operações de processamento das imagens foram realizadas no software livre QGIS 2.18 (QGIS Development Team, 2017). As bandas disponíveis no formato de arquivo jp2, foram convertidas para geotiff. Devido a diferença de resolução espacial entre as bandas do VNIR (10m) e dos SWIR e SWIR-2 $(20 \mathrm{~m})$, foi necessária reamostragem para $10 \mathrm{~m}$. Utilizou-se a técnica de reamostragem por pixels que mantém os valores de níveis digitais não resultando em dados estatísticos alterados (Figura 3). É importante frisar que este procedimento não melhora a resolução espacial, mas para compatibilizar a resolução espacial dos pixels.
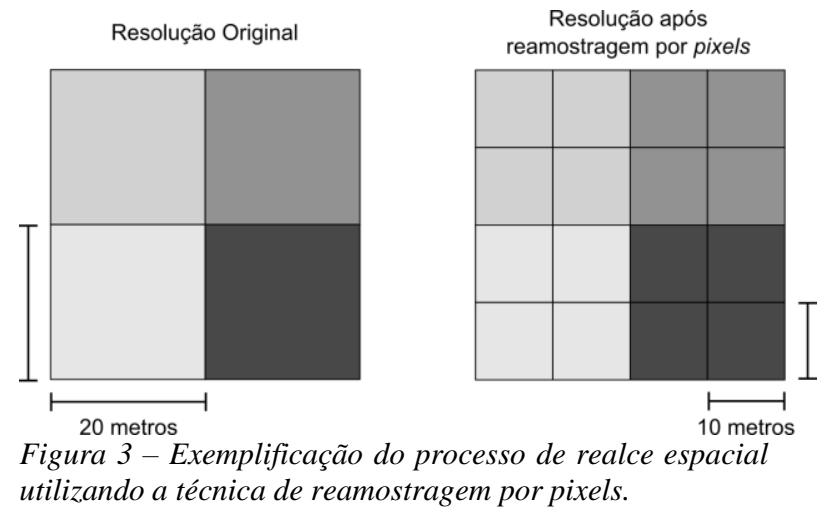

Figura 3 - Exemplificação do processo de realce
utilizando a técnica de reamostragem por pixels.

Criadas as bandas SWIRM e SWIR 2M com resolução padronizada para $10 \mathrm{~m}$ foi possível gerar uma imagem com seis bandas espectrais (Red, Green, Blue, NIR, SWIRM e SWIR 2M). Foram selecionadas seis composições falsa-cor para análise, sendo uma com bandas do VIS, uma com faixas do VNIR e outras quatro com as bandas reamostradas SWIRM e SWIR 2M. (Figura 4). 


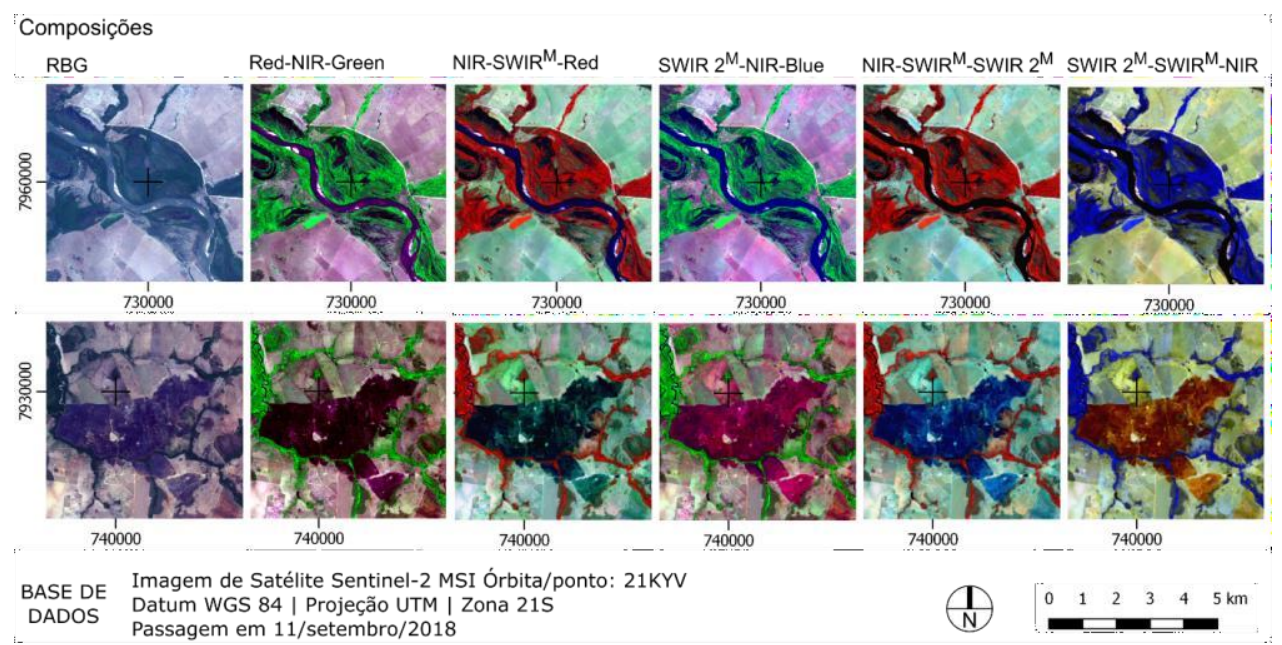

Figura 4 - Quadro com as seis composições falsa-cor com bandas Sentinel-2 MSI que serão analisadas: R(4)G(3)B(2), Red(4)NIR(8)Green(3), NIR(8)SWIRM(11)Red(4), SWIR $\quad 2 M(12) N I R(8) B l u e(2), \quad N I R(8) S W I R M(11) S W I R \quad 2 M(12) \quad e \quad S W I R$ $2 M(12) \operatorname{SWIRM}(11) N I R(8)$.

Para melhorar a acuidade visual do analista de imagens, na identificação de alvos na etapa de fotointerpretação, os níveis de cinza das imagens foram manipulados através de realce linear MinMax. A técnica consiste em redistribuir linearmente os níveis de cinza mantendo suas posições relativas (INPE, 2019).

\section{RESULTADOS}

$\mathrm{Na}$ composição $\mathrm{R}(4) \mathrm{G}(3) \mathrm{B}(2)$ (cor verdadeira) a água, a vegetação e o solo exposto apresentam pouca variação de tonalidades e cores, não possibilitando uma distinção das superfícies estudadas (Figura 5). Pequenos caminhos d'agua tornam-se imperceptíveis em meio à vegetação, assim como lagoas presentes em torno do curso do rio. A composição RGB, cor verdadeira, em geral possui pouca variação de tonalidades e cores não possibilitando uma interpretação adequada de classes do terreno, como por exemplo, os diferentes tipos de vegetação, que é mais bem visualizado na composição falsa-cor. $\mathrm{O}$ recorte $\mathrm{A}$ apresenta um grande curso d'água e massa vegetativa cercada de várias porções de área úmida enquanto no recorte $\mathrm{B}$ há principalmente áreas com marcas de incêndio ou queimada, cicatriz de incêndio e resquícios de vegetação arbórea nativa.

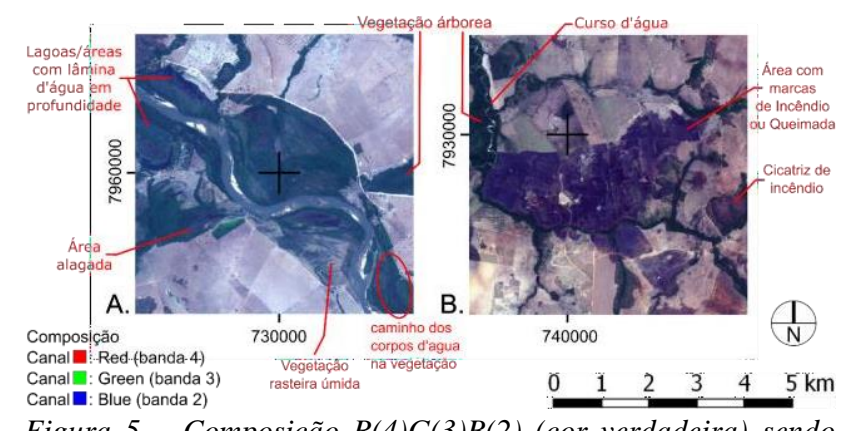

Figura 5 - Composição $R(4) G(3) B(2)$ (cor verdadeira) sendo todas bandas do VIS do Sentinel-2 MSI.

No recorte $\mathrm{B}$ da Figura 5 há marcas de incêndio que apresentam um tom mais azulado quando comparado às áreas verdes escuras com vegetação. Nessa época do ano da qual a imagem foi coletada (setembro), é recorrente ocorrer queimadas por conta da baixa umidade relativa do ar e poucas chuvas. $\mathrm{Na}$ Figura 6 estão os pontos de focos de queimadas da mesma época da coleta da imagem (11 de setembro). Nota-se que os focos estão bem no recorte de análise $\mathrm{B}$. 

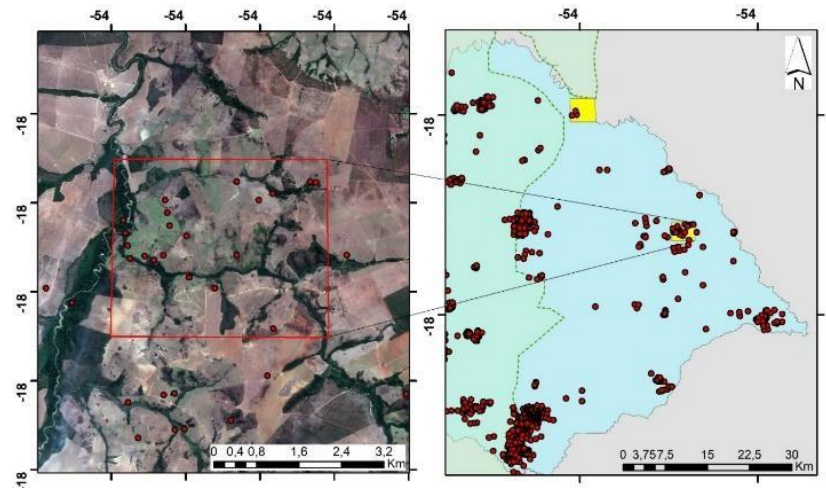

Legenda

- Focos de queimadas

3 Recortes de análise

Delimitaçăo do Pantana

Municipio de Rio Verde de Mato Gross

$\checkmark 3$ Mato Grosso do Sul

Sistema de Coordenadas SIRGAS 2000,215
Produçăo: LabGIS (Laboratório de Geoprocessamento para Aplicą̧óes Ambientais, UFMS
de queimadas na área de análise B

Figura 6 - Focos de queimadas na área de análise $B$ evidenciando que nessa região para a mesma época houve queimadas.

Fonte:

http://queimadas.dgi.inpe.br/queimadas/bdqueimadas/

Em sequência, a composição RED(4) NIR(8) GREEN(3) é composta apenas de bandas VNIR com resolução espacial $10 \mathrm{~m}$ (Figura 7). Essa composição realça a vegetação com coloração verde (NIR no canal verde), e apresenta grande reflectância das massas fotossinteticamente ativas. As áreas úmidas apresentam pouca diferenciação de regiões com solo exposto e marcas de incêndio (ambas em coloração roxa), sendo esta diferenciada principalmente pela textura. Nesta composição as marcas de incêndio recentes (matiz roxa) também são bem diferenciadas das cicatrizes de incêndios mais antigos (matiz esverdeada com manchas escuras, Figura 7B), tornando perceptível o crescimento inicial de vegetação na região. A faixa NIR do canal verde destaca com grande nitidez as massas vegetativas no recorte A. Já no recorte $\mathrm{B}$ há pouca diferenciação entre marcas de incêndio e áreas úmidas devido à baixa reflectância destes nas bandas do VIS.

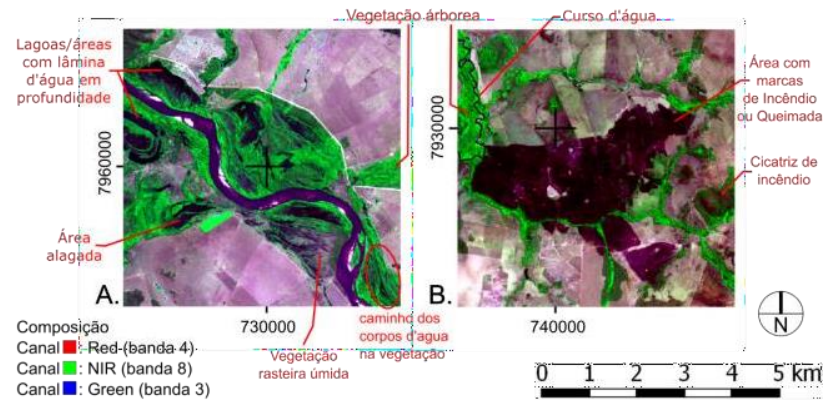

Figura 7 - Composição RED(4) NIR(8) GREEN(3) com bandas VNIR do Sentinel 2 MSI.

Na composição NIR(8) SWIRM(11) RED(4) (Figura 8) constatou-se que a água (azul escuro) e a vegetação (vermelho), apresentaram boas definições de comparações, diferenciando bem dos demais elementos de classe do solo. Já no recorte A, as lâminas d'agua (verde musgo) apresentam uma coloração diferente da água limpa (azul), porém confundem-se com marcas de incêndio do recorte $B$.

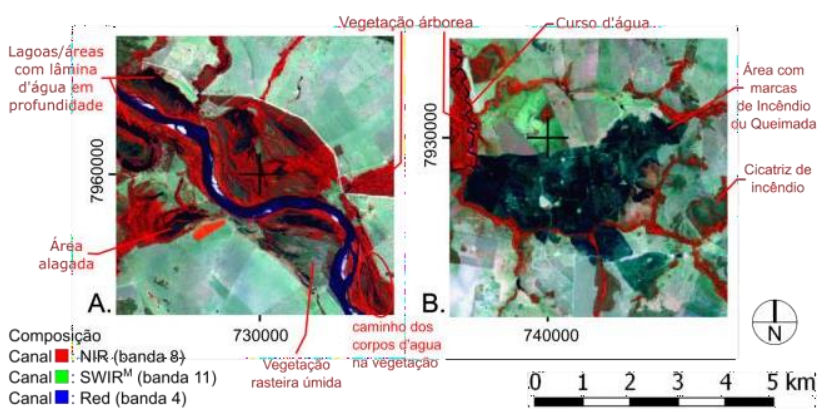

Figura 8 - Composição NIR(8) SWIRM(11) RED(4) com bandas modificadas Sentinel 2 MSI.

A água limpa do rio difere das lâminas d'água em profundidade graças ao espectro do infravermelho que quanto mais sedimentos na água o pico de reflectância se desloca na direção dos maiores comprimentos de onda. Ainda assim, as áreas com lâmina d'agua pronfuda ainda mostram coloração parecida (verde musgo) com a de marcas e cicatrizes de incêndio.

Com a composição SWIR 2M(12) NIR(8) BLUE(2) foi possível diferenciar áreas úmidas (coloração roxa) das demais feições com nitidez (Figura 9A). A sensibilidade do infravermelho distante com o próximo auxilia na distinção do solo, separando-o em uma maior gama de cores e tornando o solo exposto (coloração rosa claro) diferente das marcas de incêndio (rosa mais escuro), conforme visualizado na Figura 9B. O recorte $\mathrm{B}$ apresenta uma boa distinção dos solos com uma grande gama de cores e o diferencia consideravelmente das marcas de incêndio. Áreas úmidas, no recorte A, exibem coloração arroxeada e a água limpa um tom azulado.

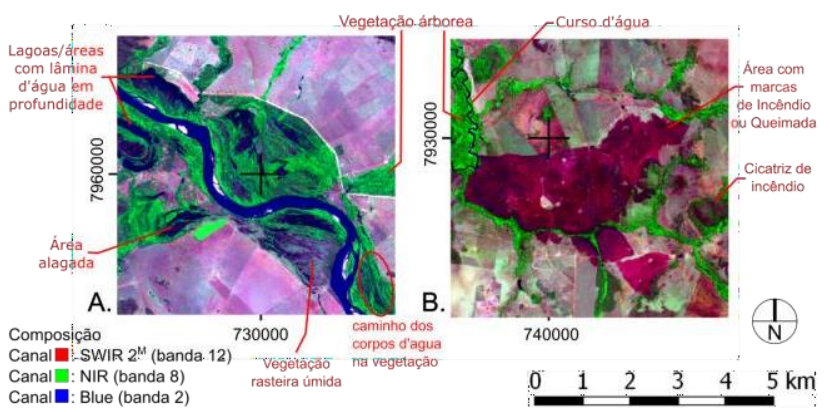

Figura 9 - Composição SWIR 2M(12) NIR(8) BLUE(2) com bandas modificadas Sentinel 2 MSI.

A composição SWIR 2M(12) SWIRM(11) NIR(8) (Figura 10) é a composição que diferencia melhor área úmida (cor verde musgo) das áreas com marcas de incêndio (coloração alaranjada). A composição destaca a vegetação em tons de azul mais escuro que a anterior SWIR 2M(12) NIR(8) BLUE(2), tornando os 
pequenos caminhos d'agua difíceis de serem identificados, além de confundir a água limpa com a água com sedimentos.

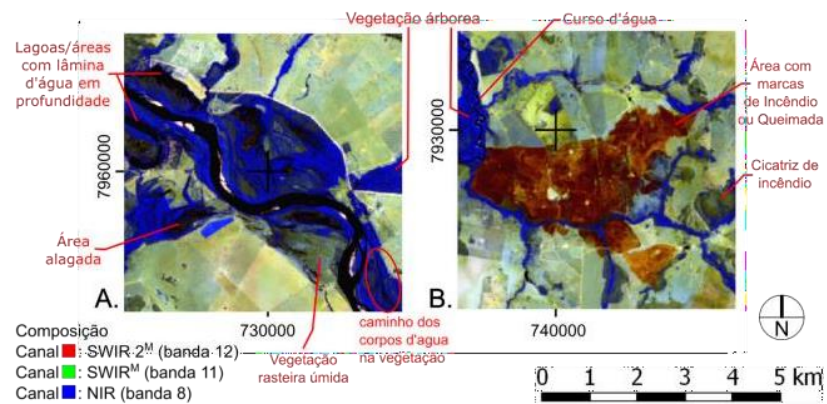

Figura 10 - Composição SWIR 2M SWIRM-NIR com bandas modificadas Sentinel 2 MSI.

A última composição NIR(8)SWIRM(11)SWIR 2M(12), também com bandas SWIR, apresenta as áreas úmidas com coloração esverdeada mais escura destoando consideravelmente de marcas de incêndio (em azul), mas se aproximando da coloração apresentada na cicatriz de incêndio (Figura 11). A Faixa NIR no canal vermelho, dá destaque à vegetação.

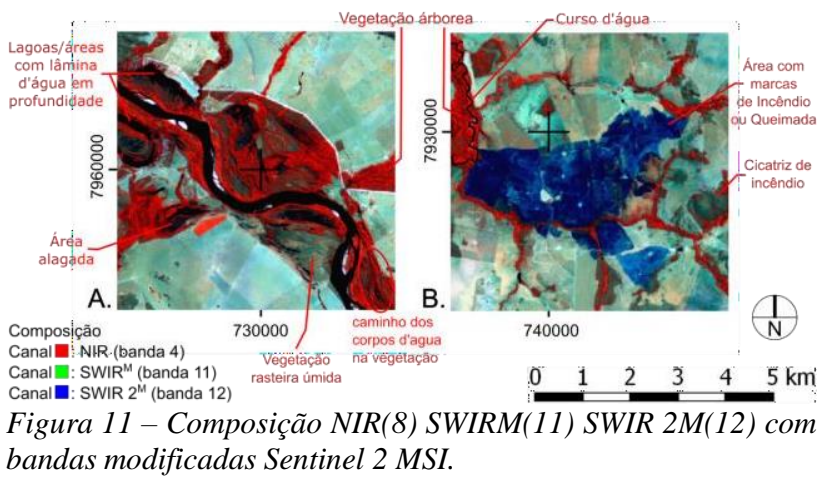

Para um melhor entendimento de quais sensores e combinações de bandas obtiveram os melhores resultados na fotointerpretação visual de pulso de inundação e queimadas, o Quadro 1 é apresentado com essas informações.

Quadro 1 - Quadro sintético das combinações de bandas e suas aplicações e também das melhores combinações na identificação visual de áreas úmidas, marcas de incêndios ou queimadas, e de cicatrizes de incêndios ou queimadas. Legenda: AP = Apropriado; NP = Não Apropriado.

\begin{tabular}{|c|c|c|c|c|c|}
\hline Composição & Alvos Detectáveis & Aplicação & $\begin{array}{c}\text { Identificação de } \\
\text { Áreas Úmidas }\end{array}$ & $\begin{array}{l}\text { Identificação } \\
\text { de Marcas de } \\
\text { Incêndios ou } \\
\text { Queimadas }\end{array}$ & $\begin{array}{c}\text { Cicatrizes } \\
\text { de } \\
\text { Incêndios } \\
\text { ou } \\
\text { Queimadas }\end{array}$ \\
\hline $\mathrm{R}(4) \mathrm{G}(3) \mathrm{B}(2)$ & $\begin{array}{l}\text { Água, vegetação e solo } \\
\text { possuem } \\
\text { variação } \\
\text { tonalidades. Pequenos } \\
\begin{array}{l}\text { caminhos d'água são } \\
\text { imperceptíveis em } \\
\text { meio à vegetação }\end{array}\end{array}$ & Pouca aplicação & NP & NP & NP \\
\hline $\begin{array}{l}\text { RED(4) NIR(8) } \\
\text { GREEN(3) }\end{array}$ & $\begin{array}{l}\text { Identificação da } \\
\text { vegetação } \\
\text { fotossinteticamente } \\
\text { ativa. Baixa } \\
\text { diferenciação entre } \\
\text { marcas de incêndio e } \\
\text { áreas úmidas devido à } \\
\text { baixa reflectância } \\
\text { destas bandas }\end{array}$ & $\begin{array}{l}\text { Aplicação no } \\
\text { monitoramento de } \\
\text { vegetação devido a } \\
\text { banda NIR no canal } \\
\text { verde dar ótima } \\
\text { resposta à vegetação } \\
\text { fotossinteticamente } \\
\text { ativa }\end{array}$ & NP & NP & NP \\
\hline
\end{tabular}




\begin{tabular}{|c|c|c|c|c|c|}
\hline $\begin{array}{c}\operatorname{NIR}(8) \\
\text { SWIRM(11) } \\
\operatorname{RED}(4)\end{array}$ & 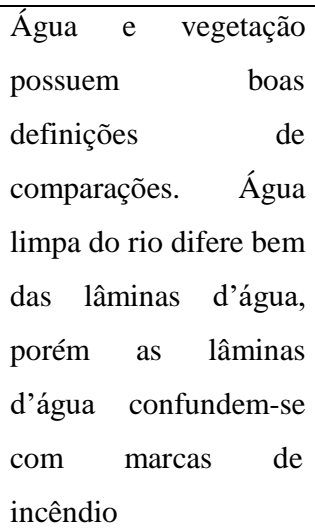 & $\begin{array}{l}\text { Boa combinação para } \\
\text { classificação } \\
\text { supervisionada, } \\
\text { principalmente para as } \\
\text { classes de vegetação, } \\
\text { água, áreas úmidas, e } \\
\text { solo exposto }\end{array}$ & $\mathrm{AP}$ & NP & NP \\
\hline $\begin{array}{c}\text { SWIR 2M(12) } \\
\text { NIR(8) BLUE(2) }\end{array}$ & $\begin{array}{l}\text { Diferencia bem as áreas } \\
\text { úmidas, marcas de } \\
\text { incêndios ou } \\
\text { queimadas e cicatrizes } \\
\text { de incêndio }\end{array}$ & 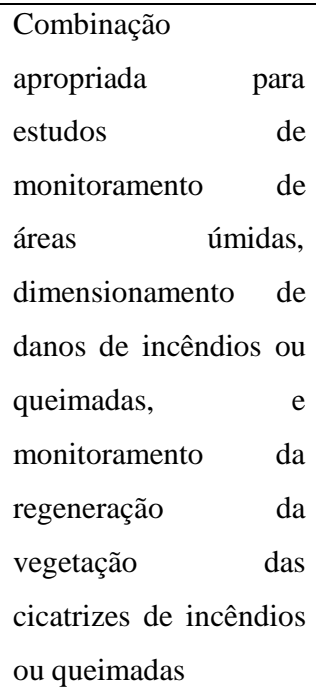 & $\mathrm{AP}$ & $\mathrm{AP}$ & $\mathrm{AP}$ \\
\hline $\begin{array}{c}\text { SWIR 2M(12) } \\
\text { SWIRM-NIR }(11,8)\end{array}$ & $\begin{array}{l}\text { Áreas úmidas e marcas } \\
\text { de incêndio ou } \\
\text { queimadas. Confusão } \\
\text { na identificação das } \\
\text { classes de vegetação } \\
\text { com caminhos d'água e } \\
\text { entre áreas úmidas e } \\
\text { cicatrizes de incêndios } \\
\text { ou queimadas }\end{array}$ & $\begin{array}{l}\text { Monitoramento das } \\
\text { áreas em que houve } \\
\text { queimadas } \\
\text { incêndios; } \\
\text { monitoramento de } \\
\text { áreas úmidas }\end{array}$ & $\mathrm{AP}$ & $\mathrm{AP}$ & NP \\
\hline $\begin{array}{c}\mathrm{NIR}(8) \\
\text { SWIRM(11) SWIR } \\
2 \mathrm{M}(12)\end{array}$ & $\begin{array}{l}\text { Boa diferenciação entre } \\
\text { áreas úmidas e marcas } \\
\text { de queimadas ou } \\
\text { incêndios; Vegetação } \\
\text { com boa diferenciação }\end{array}$ & $\begin{array}{l}\text { Levantamento de } \\
\text { fitomassa, área de } \\
\text { vegetação } \\
\text { fotossinteticamente } \\
\text { ativa; monitoramento }\end{array}$ & $\mathrm{AP}$ & $\mathrm{AP}$ & NP \\
\hline
\end{tabular}




\begin{tabular}{|l|l|l|l|l|}
\hline & e destaque devido a & de queimadas e \\
faixa NIR no canal & incêndios; \\
vermelho & & $\begin{array}{l}\text { monitoramento de } \\
\text { áreas úmidas }\end{array}$ & & \\
\hline
\end{tabular}

\section{DISCUSSÕES}

O processo de realce espacial permitiu que tivéssemos a disposição um maior número de bandas com resolução espacial similar $(10 \mathrm{~m})$ aumentando as possibilidades para a composição falsa-cor e viabilizando a diferenciação de mais alvos espectrais. Teoricamente, nesse processo haveria perda de resolução espectral. Porém na prática, neste trabalho esta perda não foi significativa e permitiu uma melhor identificação dos alvos espectrais em estudo. Salienta-se que por serem composições com bandas espectrais de um satélite relativamente recente (lançado em 2015) as vantagens constatadas podem advir da resposta à radiação eletromagnética do sensor multiespectral MSI.

As composições geradas com as bandas modificadas SWIRM e SWIR 2M identificaram alvos que seriam inviáveis com apenas as bandas da região do VNIR. Nas composições $R(4) G(3) B(2)$ e $\mathrm{R}(4) \mathrm{N}(8) \mathrm{G}(3)$ as áreas úmidas apresentaram pouca diferenciação de regiões com solo exposto e marcas de incêndio. $O$ estudo até o momento indica a composição SWIR 2M(12)NIR(8)BLUE(2) como a melhor resposta fotointerpretativa de áreas úmidas, apresentando e possibilitando diferenciá-las com nitidez das diversas coberturas do solo.

Embora diferentes métodos tenham sido utilizados para o mapeamento de áreas úmidas, o uso de dados de sensoriamento remoto através de imagens de satélite, devido à resolução espacial média do legado Landsat, ASTER ou outros satélites, ainda é difícil, para análise em escala refinada, separar áreas úmidas de outros tipos de cobertura do solo, sem o uso de dados adicionais, provenientes de medidas de campo, modelos digitais de elevação, LIDAR, etc. (Tiner et al., 2015; Kaplan \& Avdan, 2018). A técnica de reamostragem por pixels no realce de imagens orbitais, para identificação de alvos e suporte ao monitoramento de áreas úmidas a partir de dados do Sentinel-2 com resolução espacial de $10 \mathrm{~m}$ tem sido utilizada em vários estudos (Wang et al., 2016; Kaplan, 2018; Wald, 2000). Embora todos os estudos tenham mostrado resultados semelhantes, uma comparação recente entre as metodologias utilizadas, mostraram que o uso da média das bandas de alta resolução para produzir a banda pancromática ausente fornece os melhores resultados. Quanto ao método de reamostragem por pixels, forneceu valores quantitativos e qualitativos próximos aos valores ideais (Kaplan, 2018).

Zonas úmidas são difíceis de separar das outras coberturas similares, e o realce de imagens em reamostragem por pixels com imagens Sentinel-2 tem sido usado no mapeamento da cobertura e umidade do solo (Gao et al., 2017 ; Clerici et al., 2017). O uso da faixa térmica em conjunto com outras faixas do espectro facilita a visualização de áreas úmidas e das áreas com marcas de queimadas ou de incêndios. A combinação das faixa de valores de radiância NIR e SWIR pode fornecer maior diferenciação de áreas com marcas e cicatrizes de queimadas e de incendios de outros elementos, conseqüentemente, a distinção mais precisa no subconjunto restante. $\mathrm{O}$ processo de classificação e combinação de bandas eletromagnéticas compartimentaliza a paisagem com base em sua variabilidade e, portanto, se a variância dentro da classe para uma determinada banda tiver sido substancialmente reduzida, sugere que essa banda é fundamental para caracterizar a classe que se pretende identificar. Uma vez que as diferentes combinações fornecem um conjunto que mostra que a combinação da banda térmica contribui com a maior parte da variância em todo o subconjunto da áreas amostrais, e ainda assim as classes de áreas com marcas de queimadas ou de incêndios mostram a banda térmica como tendo os menores desvios padrão, evidenciando a banda térmica como a chave para identificar essas classes. Embora as combinações das bandas espectrais aqui estudadas indiquem quais bandas são centrais para interpretar as classes de áreas úmidas e de áreas queimadas, é também a combinação geral de valores entre as bandas que deve finalmente determinar a identificação dassas classes. Para classes de áreas queimadas, os valores de emissão térmica precisam ser menores do que aqueles de outras classes de área exposta, embora também tenham valores de SWIR mais baixos em relação a outros tipos de superfície (Roy et al., 2019).

Essas combinações espectrais aumentam a confiança na classificação na ausência de dados de verdade terrestre da área queimada, ou seja, pode-se ter mais certeza de que as classes de área queimada "altamente provável" realmente estão todas queimadas e não incluem outros tipos de superfície/classes. No entanto, persiste a questão da subestimação da extensão das áreas queimadas. Isso ocorreria quando os valores de pixel refletem tipos de cobertura mistos, seja porque apenas uma parte de sua área foi queimada, ou porque eles estão em áreas de incêndios anteriores que podem já ter alguma rebrota da vegetação (Stroppiana et al., 2002; Li et al., 2000).

\section{CONSIDERAÇÕES FINAIS}

Após análise detalhada, as técnicas de combinações das bandas espectrais aqui trabalhadas, forneceram informações importantes sobre quais são as melhores combinações na identificação de áreas queimadas e áreas úmidas. Isso foi proporcionado por uma interpretação fotointerpretativa cuidadosa dos dados analisados. Como todos os dados de imagem Sentinel2 estão disponíveis gratuitamente, as técnicas de identificação de áreas úmidas e de machas e cicatrizes de queimadas e incêndios descritas aqui, podem ser derivadas para qualquer outra área de estudo com características diferentes das aqui analisadas, uma vez que o comportamento espectral dos elementos de queimadas e de áreas úmidas são similares. Este trabalho pode ser estendido por 
uma porção maior e por períodos de tempo mais longos para produzir um banco de dados mais rico para pesquisas de ecologia do fogo e ecologia de áreas úmidas. Os dados resultantes são a base para pesquisas em andamento focadas no desenvolvimento de técnicas na identificação e delineamento de áreas úmidas e de manchas e cicatrizes de queimadas e incêndios, e, o mais importante, monitoramento digital da dinâmica de cobertura do solo.

A abordagem de classificação e combinação espectral de bandas modificadas, deve ser útil para outros pesquisadores que trabalham com áreas úmidas e áreas queimadas em áreas úmidas. $\mathrm{O}$ método se beneficiaria com testes em outros estudos de caso, particularmente onde a verificação de solo em tempo real de áreas queimadas e úmidas pode ser feita. Uma análise de série de curto prazo que monitorou o recrescimento da vegetação após um incêndio em uma única estação seca permitiria uma maior confiança na interpretação das classes de área queimada "possível" e, assim, reduzir a probabilidade de erros de omissão.

\section{REFERÊNCIAS}

CLERICI, N.; VALBUENA CALDERÓN, C. A.; POSADA, J. M. Fusion of Sentinel-1A and Sentinel-2A data for land cover mapping: a case study in the lower Magdalena region, Colombia. Journal of Maps, v. 13, n. 2, 718726, 2017.

ESA. European Space Agency. Sentinel 2 MSI User Guides. Disponível em <https://sentinel.esa.int>. Acesso em: 20 jul. 2019.

GAO, Q.; ZRIBI, M.; ESCORIHUELA, M. J.; BAGHDADI, N. Synergetic use of Sentinel-1 and Sentinel-2 data for soil moisture mapping at $100 \mathrm{~m}$ resolution. Sensors, v. 17, n. 9, 1966, 2017.

GUO, M. et al. A Review of Wetland Remote Sensing. Sensors, v. 17 , p. $777,2017.10 .3390 / \mathrm{s} 17040777$

INPE. Teoria: Processamento de Imagens. Disponível em: <http://www.dpi.inpe.br/spring/teoria/realce/realce.htm>. Acesso em: 5 de ag. 2019.

KAPLAN, G.; AVDAN, U. Sentinel-1 and Sentinel-2 Data Fusion for Mapping and Monitoring Wetlands, Preprints, $2018070244,2018$.

KAPLAN, G. Sentinel-2 Pan Sharpening-Comparative Analysis. Proceedings, v. 2, 345, 2018.

LI, Z.; NADON, S.; CIHLAR, J.; STOCKS, B. Satellitebasedmapping of Canadian boreal forest fires: evaluationand comparison of algorithms. Int J Remote Sens, v. 21, n. 16, 3071-3082, 2000.

MILLENNIUM ECOSYSTEM ASSESSMENT. Ecosystems and Human Well-Being: Wetlands and Water. Washington DC, 2005.
PARANHOS FILHO, A. C. et al. Sensoriamento Remoto do Complexo Aporé-Sucuriú. In: Biodiversidade do Complexo Aporé-Sucuriú : subsídios à conservação e ao manejo do Cerrado: área prioritária 316-Jauru. Org: Teresa Cristina Stocco Pagotto, Paulo Robson de Souza. Campo Grande, MS: Ed. UFMS, 2006. 308 p.

QGIS Development Team. QGIS Geographic Information System. Open Source Geospatial Foundation. Versão 2.18.23. 14-Las Palmas. 2017. Disponível em: <http://www. qgis.org/pt_BR/site/index.html>.

RAMSAR CONVENTION. The 4th Strategic Plan 2016 - 2024. Gland, Switzerland, 2016.

ROY, D. P.; HUANG, H.; BOSCHETTI, L.; GIGLIO, L.; YAN, L.; ZHANG, H. H.; LI, Z. Landsat-8 and Sentinel-2 burned area mapping - A combined sensor multi-temporal change detection approach. Remote Sensing of Environment, v. 231, $111254,2019$.

SLAGTER, B.; TSENDBAZAR, N.; VOLLRATH, A.; REICHE, J. Mapping wetland characteristics using temporally dense Sentinel-1 and Sentinel-2 data: A case study in the St. Lucia wetlands, South Africa. Int $J$ Appl Earth Obs Geoinformation, v. 86, 102009, 2020.

SAUSEN, T. M. Sensoriamento remoto e suas aplicações para recursos naturais. Apostila de sensoriamento remoto INPE. Disponível em: http://www3.inpe.br/unidades/cep/atividadescep/educasere/ apostila.html. Acesso em: 5 ag. 2019, v. 29, n. 05, 2007.

SILVA, I. T. et al. Identification of Continental Wetlands Using Different Orbital Remote Sensors.Terr@Plural, v.15, p. 125, e2115518, 2021. 10.5212/TerraPlural.v.15.2115518.001

STROPPIANA, D.; PINNOCK, S.; PEREIRA, J. M. C.; GRÉGOIRE, J-M. Radiometric analysis of SPOTVEGETATION images for burnt area detection in northern Australia. Remote Sens Environ, v. 82, n. 1, 21-37, 2002.

TINER, R. W.; LANG, M. W.; KLEMAS, V. V. Remote Sensing of Wetlands: Applications and Advances. CRC Press, 2015. $574 \mathrm{p}$.

USGS. United States Geological Survey. Imagens Sentinel $2 A$ sensor MSI. Órbita/Ponto: $21 K Y$ V. Data de Passagem $11 \mathrm{de}$ setembro de 2018. Disponível em: <https://earthexplorer.usgs.gov/>. Acesso em: 10 abr. 2019. 
WALD, L. Quality of high resolution synthesised images: Is there a simple criterion? in Third conference" Fusion of Earth data: merging point measurements, raster maps and remotely sensed images". Sophia Antipolis, 99-103, 2000.

WANG, Q.; SHI, W.; LI, Z.; ATKINSON, P. Fusion of Sentinel2 images. Remote sensing of environment, v. 187, 241-252, 2016.

\section{AGRADECIMENTOS}

Os autores agradecem ao Programa de Pós-Graduação em Tecnologias Ambientais (PPGTA), da Faculdades de Engenharias, Arquitetura e Urbanismo (FAENG) da Fundação Universidade Federal de Mato Grosso do Sul (UFMS).

Agradecem também ao Programa de Pós-Graduação em Gestão e Tecnologia Ambiental (PGGTA), da Universidade Federal de Rondonópolis, Mato Grosso.
O presente trabalho foi realizado com apoio da Coordenação de Aperfeiçoamento de Pessoal de Nível Superior - Brasil (CAPES) - Código de Financiamento 001.

Agradecemos ainda a CAPES pela bolsa de doutorado de Dhonatan Diego Pessi, processo número 88887.494036/2020-00, e ao CNPq (Processos 441975/2018-6 e 315170/2018-2).

Agradecemos também a CAPES pelo acesso ao Portal de Periódicos.

Também, ao CNPq (Conselho Nacional de Desenvolvimento Científico e Tecnológico) pela bolsa de produtividade em pesquisa de A. C. Paranhos Filho (CNPq Processo 305013/2018$1)$.

Recebido em: 11/11/2020

Aceito para publicação em: 05/05/2021 